\title{
MECHANICAL RESPONSES OF HUMAN HYPOTHENAR AND CALF MUSCLES IN NORMAL AND PATHOLOGICAL STATES
}

\author{
ROBERTO E. P. SICA
}

Since the time of Ranvier 19 it has been known that mammalian skeletal muscles differ largely in their speed of contraction due to the different proportions of fast and slow units within a muscle 1, 4, 8, 8, 24.

Despite that there is an extensive literature regarding the twitch characteristics in mammalian muscles, only a few studies are available in man. So far as this situation is concerned it has been shown that the twitch time course varies considerably from muscle to muscle; thus Lambert \& al. ${ }^{13}$, Mc Comas \& Thomas ${ }^{18}$ and Marsden \& Meadows ${ }^{14}$ agree that the triceps surae muscle has a prolonged time course, while muscle of the hand and foot, such as the first dorsal interosseus 18 , the adductor pollicis brevis $2,3,11,15,16,23$ and the extensor digitorium brevis 18,20 have faster time courses. Nevertheless the fastest time course for an already studied human muscle belongs to the frontalis as described by Mc Comas \& Thomas 18 .

The differences cited above have been attributed also to the variable proportions of fast and slow units within a human muscle; some attemps have been made to prove electrophysiologically the existance of two kinds of units in man. Buchtal \& al. 5, 6, 7 first activated small bundles of muscle in the adductor pollicis brevis, brachial triceps and brachial biceps and mentioned to have recorded single motor unit twitches in the brachial biceps of three human subjects by means of a weak voluntary effort 5 . However Sica and McComas ${ }^{20}$ made the first direct approach succeeding in stimulating single motor units by threshold stimulation in the extensor digitorum brevis muscle, recording their twitches by electronic averaging; thus they could demonstrate the existance of two populations of units, fast and slow, within the muscle.

Recently we have studied the human hypothenar and calf muscles characteristics in normal subjects and in some pathological conditions. The results are reported here.

\section{MATERIAL AND METHODS}

Subjects - The hypothenar muscles were investigated in 32 normal subjects aged between 14 and 60 years old; 16 were females and 16 were males. In 16 subjects the examination was performed on both hands and in 28 the number of active motor units in the hypothenar muscles was estimated following a technique described elsewhere 21 .

Seccion de Electroneurofisiología Clínica, Hospital Ramos Mejia, Buenos Aires. 
The subject rested confortably in a chair and the pronated hand was positioned on a wooden base. The hypothenar muscle were warmed up prior to and during the recording with an infra-red lamp, so as to mantain the temperature of the overlying skin at 34-370C.

The calve muscles were studied in 10 normal subjects aged between 20 and 33 years; 6 females and 4 males. In 8 of them the study was performed on both sides. Again the subject rested comfortably in a chair and the foot was positioned on a metal platform padded with rubber and overlying the strain-gauge, so the foot was in an angle of 900 regarding the leg which was in the same angle with the thigh. The skin overlying the calf muscles was warmed up with an infra-red lamp, so as to mantain the temperature at about $34 \circ \mathrm{C}$. In these subjects the number of functioning motor units was also estimated by employing a technique described elsewhere 22.

The hypothenar twitch characteristics were also investigated in 16 patients affected by neuromuscular diseases, thus 3 Duchenne dystrophies, 9 hyperthyroidsms, 1 hypothyroidims and 3 motoneurone diseases were studied. The calve muscles were explored in a small number of patients, one of them was affected by a limb-girdle dystrophy, one had the diagnosis of hyperthyroidsm and the remainer patient was affected by a motoneurone disease.

Mechanical recording systems - In order to record the isometric twitch of the hypothenar muscles the pronated hand was placed on a rectangular wooden base, $18 \mathrm{~cm}$ wide and $23 \mathrm{~cm}$ long (Fig. $1 \mathrm{~A}$ ), then fixed by a rectangular wooden block $1 \mathrm{~cm}$ thick, $18 \mathrm{~cm}$ long and $6 \mathrm{~cm}$ wide (Fig. $1 \mathrm{~B}$ ) padded with $5 \mathrm{~cm}$ thick sponge rubber (Fig. 1 C); this block could be lowered onto the dorsal aspect of the hand so as to grip it firmily and then screwed in position. The 2nd, 3rd and 4th fingers were fastened to the base by means of a self-adhesive nylon strap (Fig. $1 \mathrm{D}$ ) while the 5 th finger remained free.

The strain-gauge was attached by a ring (Fig. 1 E) round the proximal phalanx to the 5th finger. The transducer itself (Fig $1 \mathrm{~F}$ ) was attached to a vertical metal bar (Fig. $1 \mathrm{G}$ ), $50 \mathrm{~cm}$ long and $1 \mathrm{~cm}$ in diameter, perpendicular to the wooden base by means of a metal clamp (Fig. $1 \mathrm{H}$ ) which could be moved in lateral and anteriorposterior directions in order to adapt the strain-gauge to the axis of the proximal phalanx of the 5th finger. This arrangement ensured that the applied force was always exerted on the strain gauge in the same axis, irrespective of the different sizes of the hands.

The initial tension of the muscles was varied by moving the clamp along the vertical bar, so as to passively dorsiflex the proximal phalanx of the 5th finger. The straingauge (Rochester Electro-Medical Supply Co., type 12500) had a maximum capacity of $5 \mathrm{Kg}$ and formed one arm of a Wheatstone bridge energized by $12 \mathrm{~V}$ d. c. supply. It gave an output of $10 \mathrm{uv}$.

The isometric twitch of the calve muscles was recorded with a Rochester $\mathbf{E}$. M. S. strain-gauge, type 415005 , with a maximum capacity of $50 \mathrm{Kg}$, whose design was similar to that described by Lambert \& al. 13.

In order to fix the leg and foot in position a vertical force of $12 \mathrm{Kg}$ was applied to the knee through a wooden block $2 \mathrm{~cm}$ thick, $10 \mathrm{~cm}$ wide and $23 \mathrm{~cm}$ long padded with $5 \mathbf{c m}$ thick, sponge rubber (Fig. 2)

Procedure - To elicit the hypothenar twitch the stimulating electrodes were a pair of chlorided silver discs, $1 \mathrm{~cm}$ in diameter, spaced $3 \mathrm{~cm}$ appart in a plastic holder. They were coated with electrode jelly and positioned on the skin overlying the ulnar nerve at the wrist with the cathode distal. The electrodes holder was fixed in position by a self-adhesive nylon strap.

For recording the calf muscles twitch the stimulating electrodes were a pair of chlorided silver balls, $0.5 \mathrm{~cm}$ in diameter, spaced $2.5 \mathrm{~cm}$ appart and mounted in a plastic holder. They were coated with electrode jelly and holded on the skin overlying the medial popliteal nerve at the popliteal fossa.

The stimuli were rectangular voltage pulses 50,100 or 200 us in duration delivered from an electrostimulator randomly, but with a minimum interval of $10 \mathrm{~s}$. 


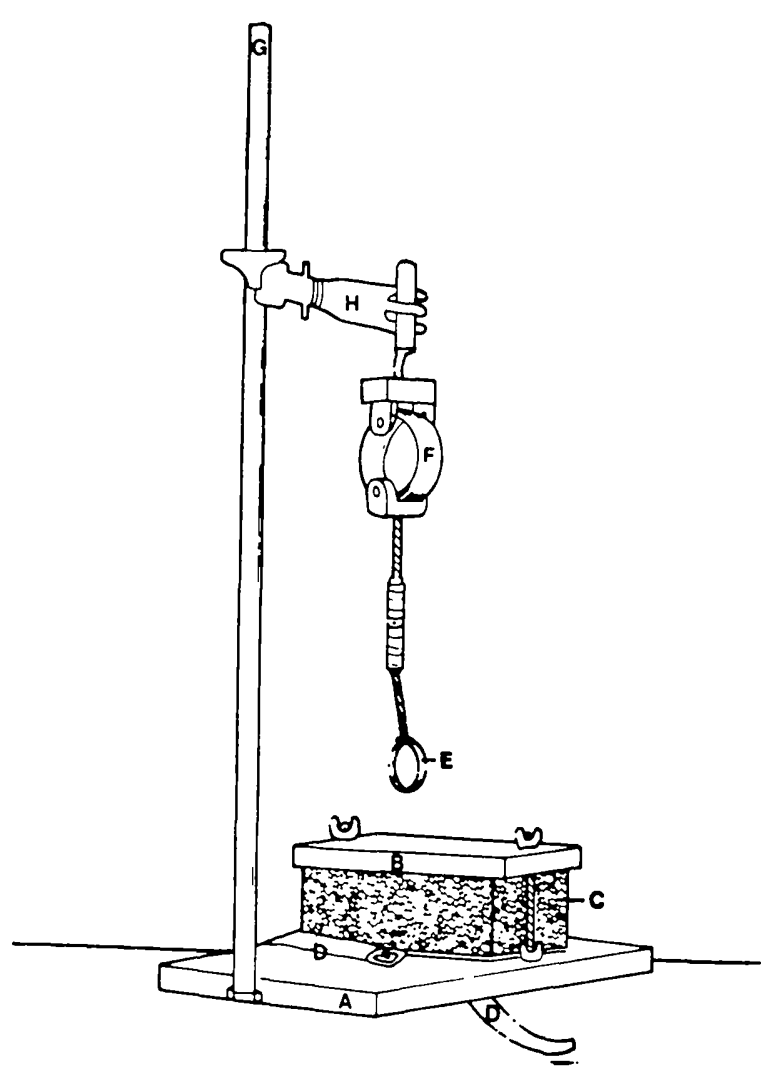

Fiy. 1 - Hypothenar muscles mechanical recording system (see text).

E'ig. 2 - Calf muscles mechanical recording system (see text).

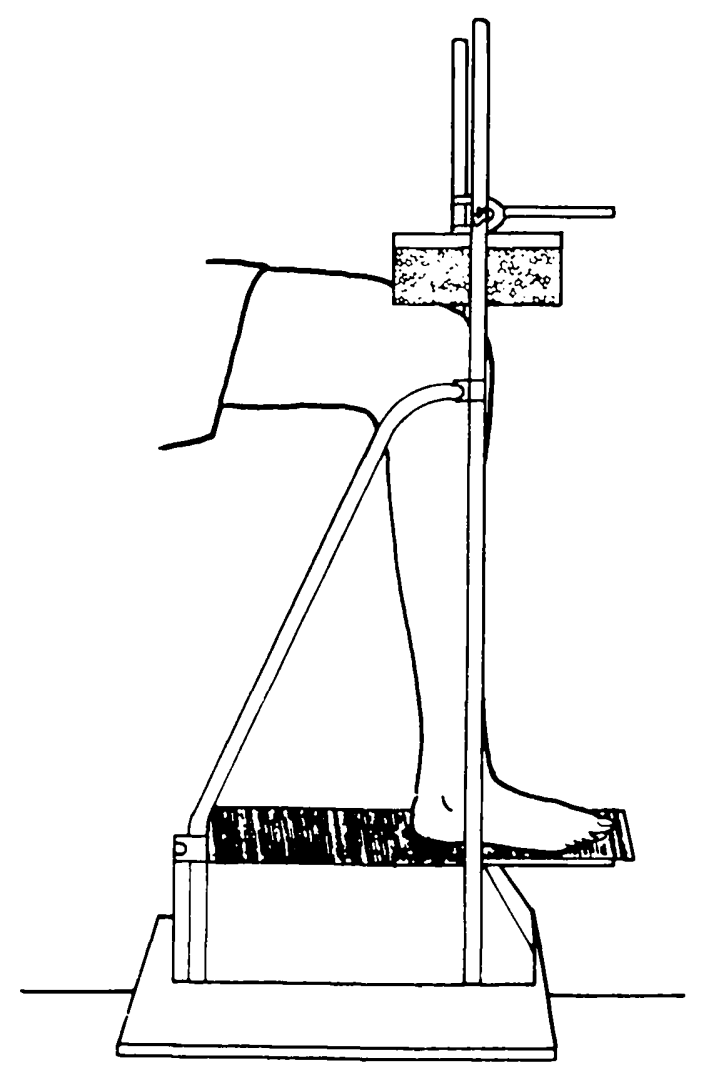

The hypothenar muscles were studied at optimal initial tensions of 1 and $1.2 \mathrm{Kg}$. No initial tension was imposed onto the calf muscles.

In separated experiments it was demonstrated that repetitive activity in the motor nerve terminals did not occur in any of the muscles investigated since the responses to single and double stimuli, 200 us appart, were identical. The presence of the $H$ response in the calf muscles was systematically checked by recording the action potential with surface eletrodes. Is was found that with supramaximal stimulation for the $M$ wave and at the nerve lowest threshold point of stimulation the $\mathbf{H}$ response did not appear. 
Treatment of the results - Throughout the text means are given with their standard deviation correlations between two variables were calculated by employing the Pearson correlation coefficient ( $r$ ). Differences between mean values were estimated by the Student $t$ test.

\section{RESULTS}

Effects of passive stretch in the hypothenar muscles - The relationship between the initial tension imposed on the muscle and the active tension developed in an isometric contraction was investigated in 8 subjects aged between 20 and 54 years. An almost linear relationship was mantained between both factors until an initial tension was obtained which corresponded to the limit of the passive dorsiflexion of the proximal phalanx of the 5th finger, no appreciable differences were found among the subjects. An example of the response obtained at the optimal initial tension of $1 \mathrm{Kg}$ is given in Fig. $\mathbf{3} \mathbf{A}$.

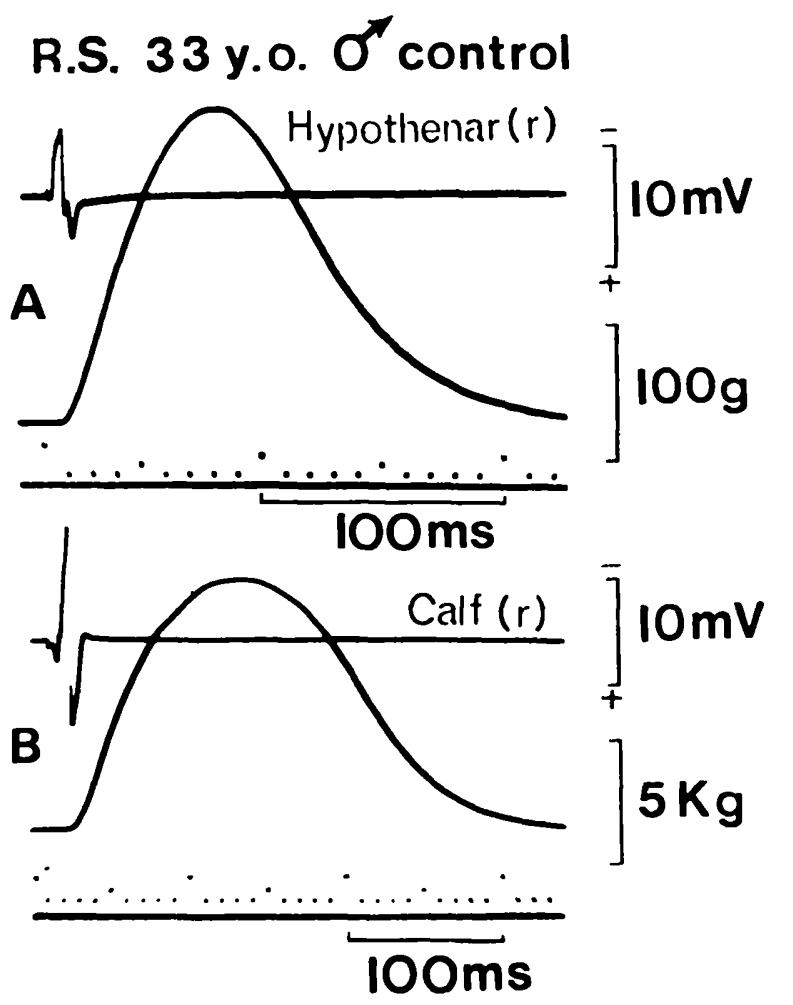

Fig. 3 - Superimposed electrical and mechanical responses of hypothenar (A) and calf (B) muscles to stimulation of ulnar and medial popliteal nerves respectively with a single supramaximal shock. Note differences in time and tension scales.

Twitch characteristics - Figure 4 shows the hypothenar twitch values of contraction and half-relaxation times in all the subjects, means are given in table 1. Altogether 50 hypothenar muscles were studied. In 16 subjects both hands were examined and the paired results were in good agreement, thus the mean discrepancy among the contraction times was $4.46 \pm 2.75 \%$, while for the half-relaxation times was $6.64 \pm 5.50 \%$. A slight significant correlation was found between contraction time and age ( $r$ : 0.354 , $\mathrm{P}:<0,02)$ but no correlation was found between half-relaxation time and age.

Several factors might be considered to explain the progressive slowness of the contraction time which occurs with age. A first possibility is that a slow and mild dennervation might take place with age, however no dennervation was noted in the studied subjects when the numbers of functioning motor units were estimated; furthermore, no signs of dennervation were observed by Sica \& al. 21 in a lerger normal population below the age of 60 years. A second possibility is that the thickness bf tissues other than the muscles increases with age; despite that this situation is very likely, the almost linear relationship between the initial tension imposed to the muscle and the tension developed by its contraction, even in the 6th decade of life, shows that this factor would play a minimal role. A final interpretation would be that mild changes in the chemical composition of the muscles fibres would take place slowly along life changing, progressively, the characteristics of the fast units into slow ones. 
Figure 4 shows the maximal twitch tension developed by the isometric contraction of the hypothenar muscles and again the paired results were in good agreement, thus the mean difference was $10.93 \pm 8.06 \%$. A significant difference $(P<0.001)$ was found when the twitch tensions were compared between females and males, being the latter (mean: 287.2g \pm 59.6, $n: 27$ ) stronger than the former (mean: $222.8 \mathrm{~g} \pm 39.8, \mathrm{n}: 23$ ).
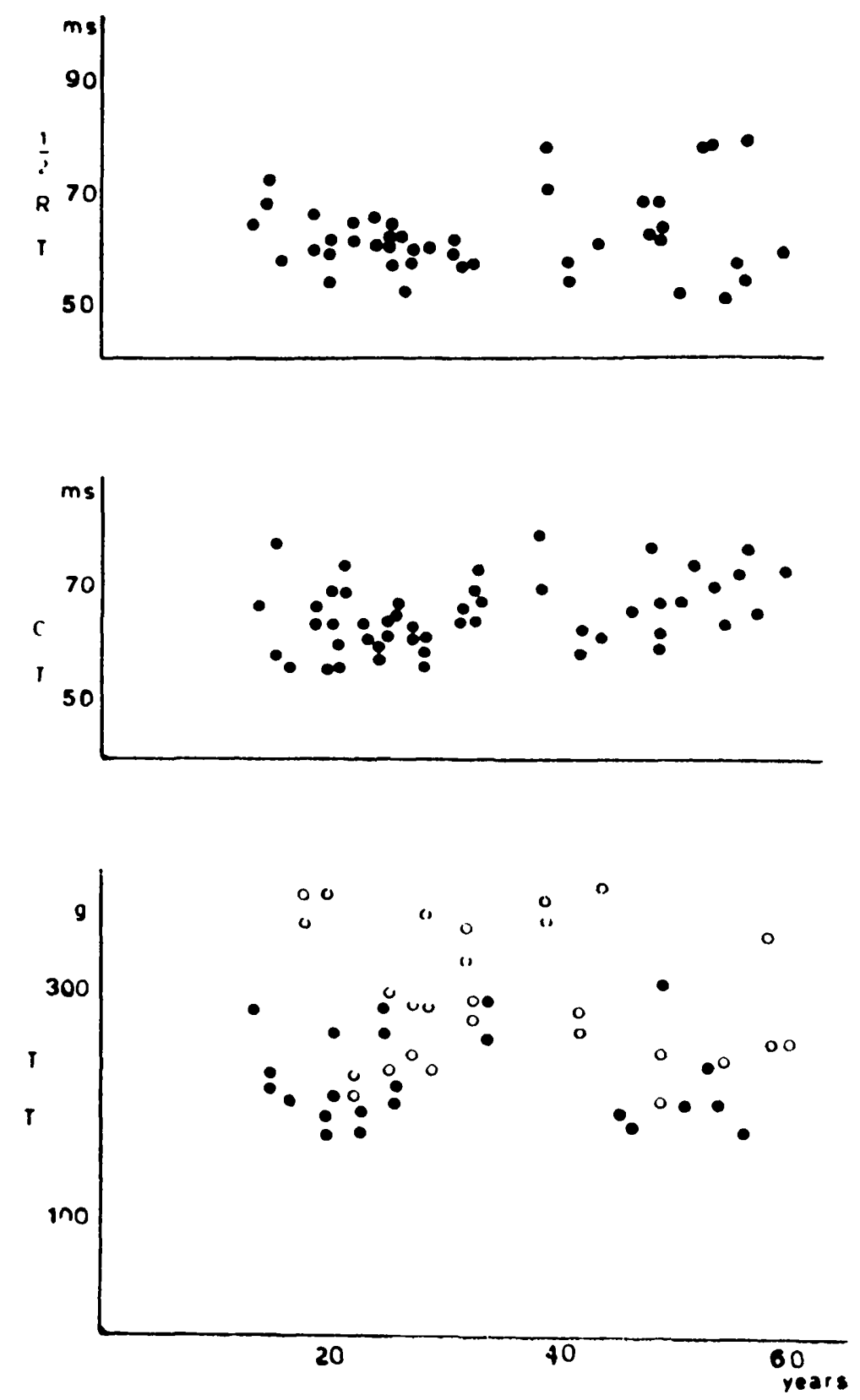

Fig. 4-Hypothenar muscles twitch parameters in normal subjects at different ages. T.T.: troitch tension, C.T.: contraction time; 1/2 R.T.: half relaxation time. In T.T. open circles are males.

Figure 5 shows the calf muscles twitch values of contraction and half-relaxation times in normal subjects, means are given in table 1. Altogether 18 muscles were investigated. In 8 subjects both sides were studied and the paired results were in good agreement, thus the mean discrepancy among contraction times was $5,56 \pm 3,95 \%$ and among half-relaxation times was $8.87 \pm 5,32 \%$, while for the tension developed by the muscles was $6.96 \pm 8,18 \%$. A significant difference was also noted between the tension developed by males $(11.4 \pm 1.13 \mathrm{Kg})$ and that developed by females $(9.5 \pm 1.6 \mathrm{Kg})$, being the former stronger than the latter $(P<0.05)$.

The comparision between the values obtained in the hypothenar and calf muscles shows a well established difference in their time courses (Table 1), being the calf muscles significantly slower than the hand muscles (Fig. $3 \mathrm{~A}, \mathrm{~B}$ ).

The above reported results might have been affected by two factors, one of them being the distance between the point where the strenght is exerted over the strain-gauge and the joint through which the muscle exerts its force. For the hypothenar muscles this distance runs between the attachment of the strain-gauge to the fifth finger and 

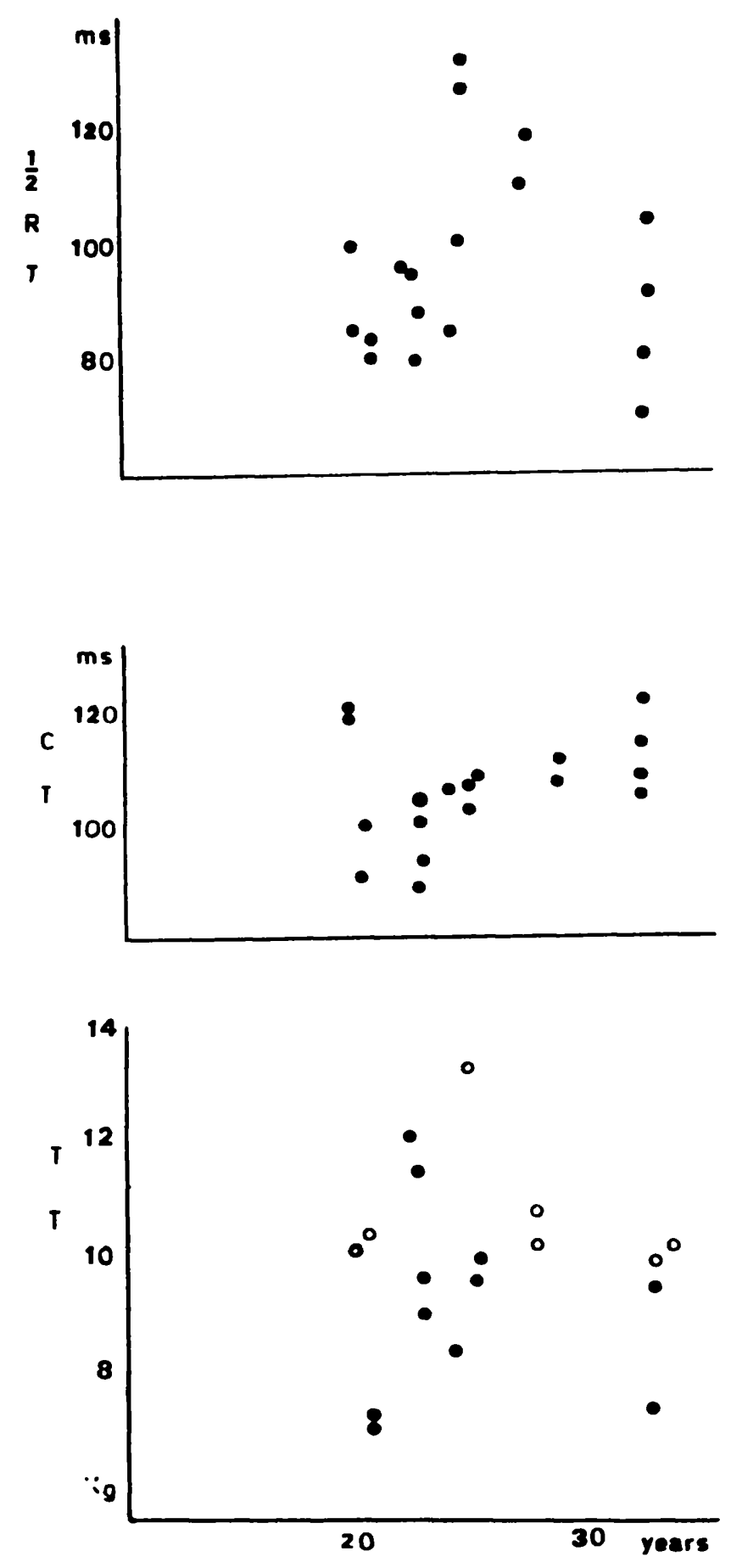

Eig. 5 - Calf muscles twitch parameters in normal subjects at different ages. T.T.: twitch tension; C. T.: contraction time; $1 / 2 R . T .:$ half relaxation time. In T.T. open circles are males.

\begin{tabular}{lcccc}
\hline Muscle & C.T. (ms) & $1 / 2$ R.T. (ms) & A.T. (Kg) \\
\hline Hypothenar & & $65.26 \pm 5.77$ & $59.62 \pm 6.51$ & $0.258 \pm 0.06$ \\
& range & $55-78$ & $50-75$ & $0.170-0.380$ \\
Calf & & $105.72 \pm 9.35$ & $95.83 \pm 16.74$ & $10.310 \pm 1.72$ \\
& range & $90-125$ & $80-130$ & $7.500-13.750$ \\
$P$ & & 0.001 & 0.001 & \\
\hline
\end{tabular}

Table $1-C . T .=$ contraction time; $1 / 2$ R.T. = half relaxation time; A.T. $=$ twoitch tension. 
the metacarpophalangeal joint, so care was taken to keep this distance constant (mean distance: $2.8 \pm 0.45 \mathrm{~cm}$ ); for the calf muscles this distance runs between the ball of the sole and the talus-tibial joint (mean distance: $11.75 \pm 1.53 \mathrm{~cm}$ ). The second factor is the elasticity of the muscle tendons and the capsules and ligaments of the mentioned joints; therefore it can be assumed that twitches from the same tendon-free muscles would have a faster time course and a higher tension. Taking into account the mentioned distances a gross estimation of the real tension developed by the muscles can be made, thus the approximated real tension developed by the hypothenar muscles should be about 3 times the measured one. while for the calf muscles the same estimation goes up to 12 times.

In 42 hypothenar muscles the number of active motor units was estimated and no correlation was found between the tension developed by the muscles and the number of units. The estimation of the number of motor units in the hypothenar muscles is based on the activity of 3 muscles which are the opponens digiti minimi (odm), the abductor digiti minimi (adm) and the flexor digiti minimi (fdm) 21; however the flexion of the proximal phalanx of the 5th finger over the 5 th metacarpal bone is mainly due to the action of the fdm and adm muscles and, in a less extent, to the 4th lumbrical muscle which is also inervated by the ulnar nerve. In the 42 hands where the numbers of active motor units were estimated the mean value was $385 \pm 78$. If it is assume 1 that each of the above mentioned muscles contributes with equal amounts to the whole population of motor units, the twitch tension would be developed by 256 units which are those belonging to the fdm and adm muscles. A gross estimation of the tension developed by a single unit would be of about $1 \mathrm{~g}$. There are many sources of error in this estimation, one of them is that the 4th lumbrical muscle contributes partially to the flexion of the phalanx and its contribution will reduce the calculated single unit tension; on the contrary the distance between the attachment of the straing-gauge to the 5th finger and the metacarpophalangeal joint and the elasticity of the tendon and other tissues will make the calculated value lower than the real one; however if the same consijerations applied to calculate the real whole muscles twitch tension are employed here, it can be assumed that a single unit might develope a mean real tension of about $3 g$.

The flexion of the foot over the leg due to the stimulation of the medial popliteal nerve is mainly due to the activity of the gastrocnemius and soleus muscles; however there are other muscles which contribute in a less extent such as the tibialis posterior (tp), the flexor digitorum longus (fdl) and the flexor hallucis longus (thl). In the subjects whose calve muscles twitches were recorded, the number of active motor units in the soleus muscle 22 was estimated no correlation was found between the number of units and the tension developed by the isometric contraction. The estimated mean number of units was $801 \pm 167$; if it is assumed that each gastrocnemius head a similar number of units 10,12 and if it is not considered the action of the tp, fdl and fhl muscles, it can be assumed that the tension developed by the isometric contraction is due to the activity of about 2400 motor units; thence a gross estimation of the mean tension developed by a single unit would be of about 4.3g; therefore, if the same considerations employed to calculate the real tension developed by a single unit in the hypothenar muscles are applied here, the averaged single unit tension would be of about $52 \mathrm{~g}$.

Results in pathological conditions - The hypothenar and calf muscles twitches were investigated in a few patients affected by different peripheral neurological disorders. Table 2 summarizes the findings.

It can be seen that patients with hyperthyroidsm tend to have faster twitches 17 while those affected by hypothyroidsm, Duchene dystrophy, limb-girdle dystrophy and motoneurone disease show slow twitches. 


\begin{tabular}{|c|c|c|c|}
\hline Diagnosis & C.T. (ms) & $1 / 2$ R.T. (ms) & A.T. $(\mathrm{g}$ \\
\hline & \multicolumn{2}{|c|}{ Hypothenar twitch } & \\
\hline Hyperthyroidsm & 57 & 65 & 150 \\
\hline " & 47 & 53 & 220 \\
\hline$"$ & 55 & 50 & 220 \\
\hline$"$ & 58 & 65 & 400 \\
\hline$"$ & 55 & 50 & 150 \\
\hline$"$ & 50 & 47 & 220 \\
\hline$"$ & 48 & 40 & 140 \\
\hline$"$ & 58 & 48 & 150 \\
\hline$"$ & 64 & 61 & 120 \\
\hline Hypothyroidsm & 90 & 85 & 270 \\
\hline Duchenne dystr. & 75 & 95 & 20 \\
\hline$"$ & 95 & 105 & 65 \\
\hline$"$ & 77 & 80 & 80 \\
\hline Motoneurone dis. & 84 & 66 & 360 \\
\hline " & 80 & 70 & 110 \\
\hline$" \quad n$ & 60 & 62 & 255 \\
\hline Controls (range) & $55-78$ & $50-75$ & $170-380$ \\
\hline
\end{tabular}

Calf twitch

Hyperthyroidsm

Limb-girdle dystr. Motoneurone dis. Controls (range)

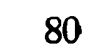

115

112

90-125

\begin{tabular}{rrr}
85 & 6000 \\
\hline & 160 & 10000 \\
\hline & 160 & 8500 \\
\hline & $80-130$ & $7500-13750$
\end{tabular}

\footnotetext{
Table $2-C . T .=$ contraction time; $1 / 2$ R.T. = half relaxation time; A.T. = twitch tension; dystr. = dystrophy; dis. = disease.
}

\section{DISCUSSION}

From the several techniques used in the past to study the mechanical characteristics of skeletal muscle contraction, the most suitable approach has been the recording of the isometric twitch; thus several methods have been deviced according to the anatomical characteristics of the explored muscles.

The obtained results are relevant in two respects, thus they proved once more the existance in man of muscles with significantly difference time courses which probably reflects a genuine variation in the proportion of fast and slow units within different muscles. In this respect the earlier work of Mc Comas and Thomas 18 is pertinent. These authors reported different twitch characteristics in muscles of the hand, face, foot and leg and concluded that human muscles can be divided into fast (frontalis) or slow (gastrocnemius) and in a third group called intermedius (first dorsal interosseus of the hand and extensor digitorum brevis); they concluded that the predominance of fast or slow units or the presence of substancial proportions of both of them within a human muscle is responsible for the above pointed differences. Our present findings agree with those reported by Mc Comas and Thomas: following their criteria the hypothenar muscles should be included in the intermedius group, while the calf muscles would integrate the slow group. 
The other point which deserves to be commented is the potential usefulness of these techniques in applied neurophysiology. Despite that with the present mechanical recording technique the real values are influenced by the several factors already mentioned, as far as the recording conditions can be mantained in different subjects, the methods have proved to be valuable in different clinical pictures.

\section{SUMMARY}

A study has been made of the isometric twitches of hypothenar and calf muscles in man. The twitch contraction time for hypothenar muscles ranged between 55 and $78 \mathrm{~ms}$, while for the calf muscles it ranged between 90 and $125 \mathrm{~ms}$. According to their speed of contractions the hypothenar muscles were considered belonging to the so called intermedious group while the calf muscles integrate the slow group. It has been also demonstrated that these techniques can successfully be applied to the investigation of several neuromuscular disorders.

\section{RESUMEN}

Se realizó un estudio de la contracción isométrica de los músculos de la eminencia hipotenar y pantorrilla en el hombre. Los tiempos de contracción para los músculos de la eminencia hipotenar variaron entre 55 y $78 \mathrm{~ms}$, en tanto que los correspondientes a la pantorrilla lo hicieron entre $l o s 90$ y $125 \mathrm{~ms}$. En base a estos tiempos los primeros fueron classificados dentro del grupo de músculos intermedios, en tanto que los últimos lo fueron en el lento. Se resalta la importancia de estas técnicas en el estudio de la patología neurológica periférica.

\section{REFERENCES}

1. ANDERSEN, P. \& SEARS, T. A. - The mechanical properties and innervation of fast and slow motor units in the intercostal muscles of the cat. J. Physiol. 173:114, 1964.

2. BOTELHO, S.; BECKETT, S. B. \& BENDLER, B. - Mechanical and electrical responses of intact thenar muscles to indirect stimuli. Neurology (Minneapolis) 10:601, 1960.

3. BOTELho, S. \& CANDER, L. - Post-tetanic potentiation before and during ischaemia in intact human skeletal muscle. J. Appl. Physiol. 6:221, 1953.

4. BUERKE, R. E. - Motor unit types of cat triceps surae muscle. J. Physiol. 193:141, 1967.

5. BUCHTAL, F. \& SCHMALBRUCH, H. - Spectrum of contraction times of different fibres bundles in the brachial biceps and triceps muscles of man. Nature $222: 89,1969$.

6. BUCHTAL, F.; SCHMALBRUCH, H. \& KAMIENIECKA, Z. - Contraction times and fiber types in patients with progressive muscular dystrophy. Neurology (Minneapolis) 21:131, 1971.

7. BUCHTAL, F.; SCHMALBRUCH, H. \& KAMIENIECKA, Z. - Contraction times and fiber types in neurogenic paresis. Neurology (Minneapolis) 21:58, 1971. 
8. BULLER, A. J.; DORNHOST, A. C.; EDWARDS, R.; KERR, D. \& WHELAN, R. F. - Fast and slow muscles in mamals. Nature 183:1516, 1959.

9. BULLER, A. J.; ECCLES, J. C. \& ECCLES, R. M. - Differentiation of fast and slow muscles in the cat hind-limb. J. Physiol. 150:399, 1960.

10. CHRISTENSEN, E. - Topography of terminal motor innervation in striated muscles from stillborn infants. Am J. Physic. Med. 38:65, 1959.

11. DESMEDT, J. \& HAINANT, $\mathbf{K}$. - Kinetics of myofilaments activation in potentiated contraction: staircase phenomenon in human skeletal muscle. Nature 217:529, 1968.

12. FEINSTEIN. B.; LINDEGARD, B.; NYMAN, E. \& WOHLFART, G. - Morphologic studies of motor units in normal human muscles. Acta Anat. 23:127, 1955.

13. LAMBERT, E.; UNDERDAHL, O.; BECKETT, S. \& MEDEROS, L. - A study of the ankle jerk in myxoedema. J. Clin. Endocr. 11:1186, 1951.

14. MARSDEN, C. D. \& MEADOWS. J. C. - The effect of adrenaline on the contraction of human muscle. J. Physiol. 207:429, 1970.

15. MERTON, P. A. - Voluntary strengh and fatigue. J. Physiol. 23:553, 1954.

16. MERTON, P. A. \& PANPIgLIONI, G. - Strengh and Fatigue. Nature 66:527, 1950.

17. Mc COMAS, A. J.; SICA, R. E. P.; Mc NABB, A.; GOLDBERG, W \& UPTON, A. - Evidence for reversible motoneurone dysfunction in thyrotoxicosis. $J$. Neurol. Neuros. Psychiat. 37:548, 1974.

18. Mc COMAS, A. J. \& THOMAS, H. C. - Fast and slow twitch muscles in man. J. Neurol. Sci, $7: 301,1968$.

19. RANVIER, L. - Proprietés et structures differents des muscles rouges et des muscles blancs chez les lapins et chez les raies. C. R. Acad. Sci. (Paris) 77:1030, 1873.

20. SICA, R. E. P. \& Mc COMAS, A. J. - Fast and slow twitch units in a human muscle. J. Neurol. Neurol. Psychiat. $34: 113,1971$.

21. SICA, R. E. P.; Mc COMAS, A. J.; UPTON, A. \& LONGMIRE, D. - Motor unit estimations in small muscles of the hand. J. Neurol. Neurol. Psychiat. 37:55, 1974.

22. SICA, R. E. P. \& SANZ, O. P. - The effects of ageing upon the human soleus muscle. Medicina (Buenos Aires) 36:443, 1976.

23. SLOMIC, A.; ROSENFALCK, A. \& BUCHTAL, F. - Electrical and mechanical responses of normal and myasthenic muscles. Brain Res. 10:1, 1968.

24. WUERKER, R. B.; Mc PHEDRAN, A. M. \& HENNEMAN, E. - Properties of motor units in a heterogeneous pale muscle (m. gastrocnemious) of the cat. $J$. Neurophysiol. 28:85, 1965.

Seccion de Electroneurofisiología Clinica - Hospital Ramos Mejía - Urquiza 609 - Buenos Aires, Argentina. 